\title{
СИНТЕЗ И СВОЙСТВА АЛКИЛ-N-(СУЛЬФОЭТИЛ)- И -N-(КАРБОКСИМЕТИЛ)-АМИНОАЦЕТАТОВ
}

\section{1. Реакция галоидацетатов с амино- и аминосульфокислотами}

\author{
Представлена О. Эйзеном
}

В реакции сложных эфиров с первичными или вторичными аминами обычно образуются N-алкиламиды. В случае использования эфиров галоидзамещенных кислот, кроме реакции аминолиза (образование амида), происходит также замещение галоида:

$$
\mathrm{Hal}\left(\mathrm{CH}_{2}\right)_{n} \mathrm{COOR}+\mathrm{NHR}^{\prime} \mathrm{R}^{\prime \prime}-\mid \begin{aligned}
& \rightarrow \mathrm{Hal}\left(\mathrm{CH}_{2}\right)_{n} \mathrm{CONR}^{\prime} \mathrm{R}^{\prime \prime}+\mathrm{ROH} \\
& \rightarrow \mathrm{R}^{\prime} \mathrm{R}^{\prime \prime} \mathrm{N}\left(\mathrm{CH}_{2}\right)_{n} \mathrm{COOR}+\mathrm{HCl}
\end{aligned}
$$

Если используются эфиры, в которых галоид находится в $\alpha$-положении по отношению к карбонильной группе $(n=1)$, реакция замещения благодаря влиянию этой группы протекает сравнительно легко.

При использовании эфиров галоидокислот с достаточно длинным углеводородным радикалом были получены катионактивные поверхностно-активные вещества (ПАВ), однако более целесообразно использовать третичные амины, дающие возможность получить вещества типа четвертичных солей аммония :[ $\left.{ }^{1}\right]$.

Нами изучалась возможность синтеза ПАВ реакцией длинноцепочечных галоидацетатов с первичными и вторичными аминами, содержащими кислотные группы, т. е. с амино- и аминосульфокислотами. Ранее аналогичный синтез был осуществлен на основе галоидацетатов и таурина $\left[{ }^{2}\right]$. Близкие по структуре таким веществам соединения получены также присоединением амино- и аминосульфокислот к эфирам акриловой кислоты $\left[{ }^{3}\right]$. И первые, и вторые вещества могут быть рассмотрены как $\mathrm{N}$-алкиламино- или $\mathrm{N}$-алкиламиносульфокислоты $\left[{ }^{1}\right]$, содержащие в гидрофобном радикале сложноэфирную группу, т. е. как разновидности известных типов ПАВ.

В настоящем сообщении приводятся данные о влиянии на исход вышеприведенных двух реакций структуры галоидацетатов и амино- и аминосульфокислот. В качестве галоидацетатов были использованы монобром- и монохлорацетаты, оба с первичным и вторичным алкильными радикалами $\mathrm{C}_{12}$, а в качестве амино- и аминосульфокислот глицин, саркозин, таурин и метилтаурин.

\section{Экспериментальная часть}

Исходные вещества. Первичный додецилхлорацетат и первичный додецилбромацетат синтезировались из первичного додецилового спирта и хлор- и бромуксукной кислоты 
кипячением в толуоле с водоотделителем в присутствии небольшого количества $n$-толуолсульфокислоты, а затем перегонялись. Чнстота их, по данным газохроматографического аналнза, выше $99 \%$.

Вторичный додецилхлорацетат и вторичный додецилбромацетат были получены присоединением хлор- и бромуксусной кислоты к додецену-1. Их изомерный состав $(\%)$ : 2-галоидацетат 60-70, 3-галоидацетат 25-30, 4-галоидацетат 5-10. Такой состав - обычное явление при реакции 1-алкена с галондуксусными кисләтами $\left[{ }^{2}\right]$. Чистота выше $97 \%$.

Таурин и метилтаурин синтезировались из 2-хлорэтансульфокислоты и аммиака или метиламина $\left[{ }^{4}\right]$ и очищались путем многократной перекристаллизации. Использовались «хч» глицин и саркознн.

Проведение реакций и выделение продуктов. Реакции проводились в $70 \%$-ном водноспиртовом растворе, который способствует получению моноацетатов в случае применения таурина и глицина. Для связывания освобождающегося при реакции (2) хлористого водорода амино- и аминосульфокислоты добавлялись в молярном избытке. Реакционная смесь нагревалась и перемешивалась до полного превращения галоидацетата (определение производилось газохроматографически или титрованием возникающего галоид-иона). Образующийся при реакции (1) первичный или вторичный додециловый спирт экстрагировался петролейным эфиром, и определялось его количество. Реакционная смесь после извлечения из нее додецилового спирта выпаривалась досуха, и из сухого остатка экстрагировался продукт замещения: в случае веществ с вторичным алкильным радикалом - петролейным эфиром или хлороформом, с первичным алкильным радикалом - абсолютным спиртом.

Очистка продуктов замещения и их анализ. Для очистки продуктов замещения они растворялись в воде, полученный раствор подкислялся, выделившаяся внутренняя соль $\mathrm{X}\left(\mathrm{CH}_{2}\right){ }_{n} \stackrel{+}{\mathrm{N}} \mathrm{HR}^{\prime} \mathrm{CH}_{2} \mathrm{COOC}_{12} \mathrm{H}_{25} \quad\left(\mathrm{X}=-\mathrm{COO}-\right.$ или $-\mathrm{SO}_{3}{ }^{-}, n=1$ или $2, \mathrm{R}^{\prime}=\mathrm{CH}_{3}$ или Н) отфильтровывалась, промывалась и высушивалась. Путем прибавления к ее спиртовому раствору теоретического количества $\mathrm{NaOH}$ внутренняя соль была снова

Таблица 1

Данные анализа алкил-N-(сульфоэтил)- и -N-(карбоксиметил)-аминоацетатов

\begin{tabular}{|c|c|c|c|c|c|c|c|c|c|}
\hline 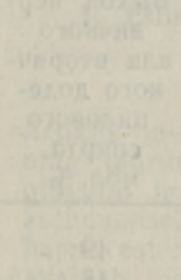 & \multirow[t]{2}{*}{ Вещество } & \multicolumn{2}{|c|}{ C } & \multicolumn{2}{|c|}{$\mathrm{H}$} & \multicolumn{2}{|c|}{$\begin{array}{c}\text { Титро- } \\
\text { вание } \\
\text { по. амин- } \\
\text { ной } \\
\text { группе, } \\
\text { ма/зкв. } \\
\text { кислоты } \\
\text { на } 1 \text { г ве- } \\
\text { щества }\end{array}$} & \multicolumn{2}{|c|}{$\begin{array}{c}\text { Количест- } \\
\text { во связан- } \\
\text { ного спир- } \\
\text { та, г на } \\
1 \text { г вещест- } \\
\text { ва }\end{array}$} \\
\hline & & $\begin{array}{l}\text { оп- } \\
\text { ред. }\end{array}$ & $\begin{array}{l}\text { тео- } \\
\text { рет. }\end{array}$ & $\begin{array}{l}\text { оп- } \\
\text { ред. }\end{array}$ & $\begin{array}{l}\text { тео- } \\
\text { рет. }\end{array}$ & $\begin{array}{l}\text { оп- } \\
\text { ред. }\end{array}$ & $\begin{array}{l}\text { тео- } \\
\text { рет. }\end{array}$ & $\begin{array}{l}\text { оп- } \\
\text { ред. }\end{array}$ & $\begin{array}{l}\text { тео- } \\
\text { рет. }\end{array}$ \\
\hline
\end{tabular}

$\mathrm{NaO}_{3} \mathrm{~S}\left(\mathrm{CH}_{2}\right)_{2} \mathrm{NHCH}_{2} \mathrm{COO}$-перв.- $\mathrm{C}_{12} \mathrm{H}_{25}$ $\mathrm{NaO}_{3} \mathrm{~S}\left(\mathrm{CH}_{2}\right)_{2} \mathrm{NHCH}_{2} \mathrm{COO}$-втор.- $\mathrm{C}_{12} \mathrm{H}_{25}$ $\mathrm{NaO}_{3} \mathrm{~S}\left(\mathrm{CH}_{2}\right)_{2} \mathrm{~N}\left(\mathrm{CH}_{3}\right) \mathrm{CH}_{2} \mathrm{COO}$-втор.- $\mathrm{C}_{12} \mathrm{H}_{25}$ $\mathrm{NaOOCCH}_{2} \mathrm{NHCH}_{2} \mathrm{COO}$-втор.- $\mathrm{C}_{12} \mathrm{H}_{25}$ $\mathrm{NaOOCCH} 2 \mathrm{~N}\left(\mathrm{CH}_{3}\right) \mathrm{CH}_{2} \mathrm{COO}$-BTop.- $\mathrm{C}_{12} \mathrm{H}_{25}$ $\begin{array}{llllllll}49,7 & 51,5 & 8,28 & 8,59 & 2,59 & 2,69 & 0,483 & 0,498\end{array}$

$\begin{array}{llllllll}48,9 & 51,5 & 8,37 & 8,59 & 2,67 & 2,69 & 0,479 & 0,498\end{array}$

$\begin{array}{llllllll}50,6 & 52,6 & 8,77 & 8,79 & 2,56 & 2,58 & 0,472 & 0,481\end{array}$

$\begin{array}{llllllll}60,1 & 59,5 & 9,71 & 9,3 & 2,80 & 3,10 & 0,589 & 0,578\end{array}$

$\begin{array}{llllllll}58,9 & 60,5 & 9,90 & 9,50 & 2,82 & 2,87 & 0,539 & 0,552\end{array}$

переведена в форму натриевой соли $\mathrm{X}\left(\mathrm{CH}_{2}\right)_{n} \mathrm{NR}^{\prime} \mathrm{CH}_{2} \mathrm{COOC}_{12} \mathrm{H}_{25} \quad\left(\mathrm{X}=-\mathrm{COONa}_{1}\right.$ или $-\mathrm{SO}_{3} \mathrm{Na}, n=1$ или $2, \mathrm{R}^{\prime}=\mathrm{CH}_{3}$ или $\mathrm{H}$ ). Результаты анализа очищенных продуктов приведены в табл. 1. Титрование по аминной группе производилось в растворе хлороформа с хлороформным раствором $n$-толуолсульфокислоты [5]; количество связанного спирта определялось его экстрагированием после полного гидролиза продукта. 


\section{Обсуждение результатов}

Взаимное протекание реакций аминолиза сложноэфирной связи и замещения галоида зависит в основном от двух факторов: скорости аминолиза и легкости замещения галоида. Скорость аминолиза, как известно, уменьшается в ряду: эфиры первичных спиртов, вторичных спиртов, третичных спиртов $\left[{ }^{6}\right]$, а легкость замещения - в ряду: йод, бром, хлор. Результаты взаимодействия первичного и вторичного додецилхлор- и бромацетата с таурином (табл. 2) показывают, что способностью к замещению в большей степени обладают эфиры бромуксусной кислоты и эфиры с вторичным алкильным радикалом, а реакция аминолиза идет быстрее в случае эфиров хлоруксусной кислоты и эфиров с первичным радикалом. Таким образом, реакция замещения является доминирующей тогда, когда галоид более подвижен и если сложноэфирная связь более устойчива к аминолизу.

Наибольшие выходы продукта замещения дает применение вторичных эфиров бромуксусной кислоты, хотя и при использовании вторичных хлорацетатов и первичных бромацетатов эти выходы удовлетворительны. Суммарный выход продукта замещения и аминолиза много меньше $100 \%$ в случае первичного хлорацетата - это, по-видимому, результат неполной его экстракции из смеси солей, а также влияния неизвестных побочных реакций.

Как показывают результаты взаимодействия вторичного додецилбромацетата с глицином, саркозином, таурином и метилтаурином (табл. 3), структура амино- и аминосульфокислот мало влияет на соотношение реакций замещения и аминолиза. Хорошие выходы продукта замещения могут быть получены не только с таурином, но и другими амино- и аминосульфокислотами.

Таблица 2

Реакция таурина с эфирами галоидуксусных кислот ( $70 \%$-ный этанол; концентрация эфиров 0,1 моль/л; эфир : таурин $\left.1: 2 ; 70{ }^{\circ} \mathrm{C}\right)$

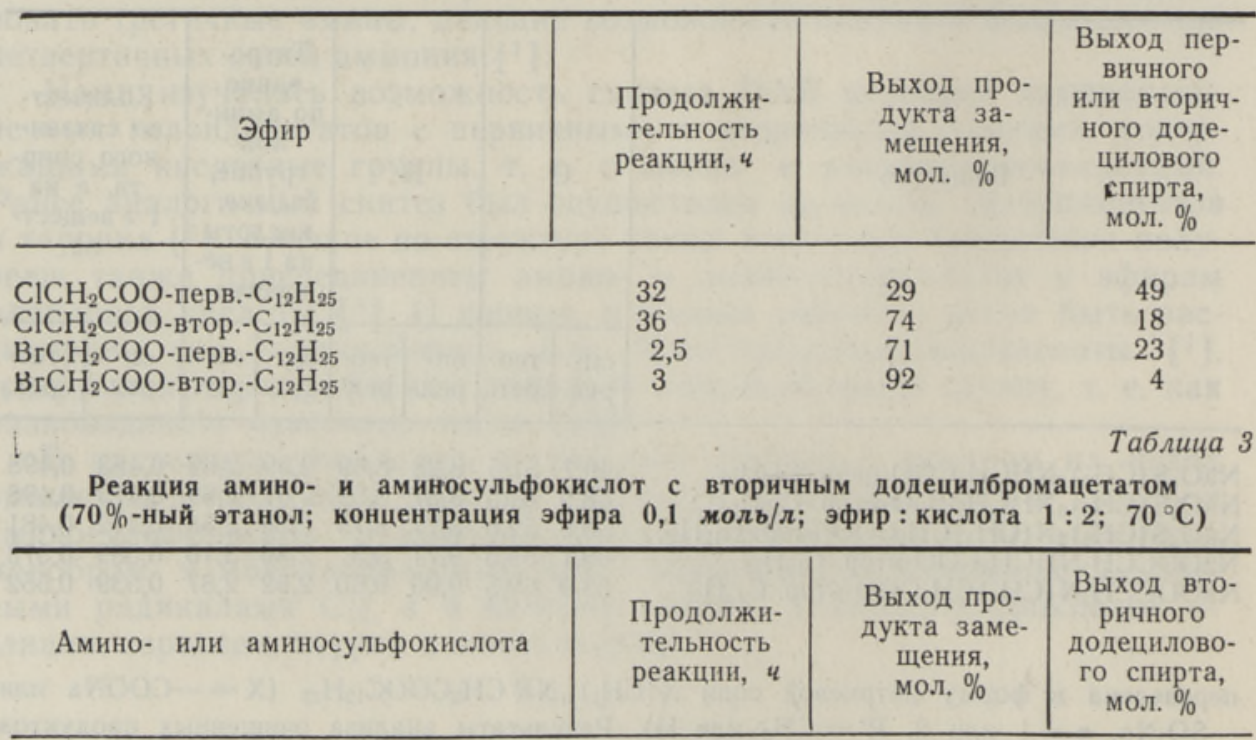

$\mathrm{H}_{2} \mathrm{NCH}_{2} \mathrm{COONa}$

$\left(\mathrm{CH}_{3}\right) \mathrm{HNCH}_{2} \mathrm{COONa}$

$\mathrm{H}_{2} \mathrm{NCH}_{2} \mathrm{CH}_{2} \mathrm{SO}_{3} \mathrm{Na}$

$\left(\mathrm{CH}_{3}\right) \mathrm{HNCH}_{2} \mathrm{CH}_{2} \mathrm{SO}_{3} \mathrm{Na}$

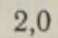

0,5

3,0

1,0
88

92

92

93
5

5

4

4 


\section{Выводы}

1. Из эфиров хлор- и бромуксусных кислот с достаточно длинным алкильным радикалом при замещении галоида амино- и аминосульфокислотами могут быть получены ПАВ.

2. Удовлетворительные выходы продукта замещения дает использование эфиров с вторичным алкильным радикалом или эфиров бромуксусной кислоты.

3. Структура амино- и аминосульфокислот на выход продукта существенно не влияет.

\section{Л И ТЕ РА Т У Р А}

1. Ш в а р ц А., П е р р и Дж. Поверхностно-активные вещества. М., 1953.

2. Фа йнгольд С. И., К и ик Х. Э. Поверхностно-активные вещества типа вторичных сульфоацетатов и сульфоэтиламиноацетатов. - Масложир. пром-сть, 1975, № 4 , c. $30-31$.

3. Кууск А., Фа й нгольд С. Синтез ПАВ на основе вторичных алкильных акрилатов. - Изв. АН ЭССР. Хим. Геол., 1977, т. 26, № 3, с. $231-234$.

4. Schick, I. W., Degering, E. F. Synthesis of taurine and N-methyltaurine. Ind. Eng. Chem., 1947, v. 39, N 7, p. 906-909.

5. Б а у е р К. Анализ органических соединений. М., 1953, с. 143.

6. Gord o n, M., Mille r, J. G., D a y, A. R. Effect of structure on reactivity. I. Ammonolysis of esters with special reference to the electron release effects of alkyl and aryl groups. - J. Amer. Chem. Soc., 1948, v. 70, N 5, p. 1946-1950.
Ннститут химии
Академии наук Эстонской ССР
Поступила в редакцию $22 / \mathrm{V} 1978$

\section{H. KIIK, Reet JOONSON, S. FAINGOLD}

\section{ALKOUL-N-(SULFOETUUL)- JA ALKUUL-N-(KARBOKSUMETOUL)-AMINO- ETANAATIDE SONTEES NING OMADUSED.}

\section{Erinevate halogenoetanaatide ja aminohapete ning aminosulfohapete vaheline reaktsioon}

Artiklis on esitatud 1) primaarsete ja sekundaarsete dodetsüülkloro- ja -bromoetanaatide ning tauriini ja 2) sekundaarse dodetsüülbromoetanaadi ning tauriini, metüültauriini, glütsiini ja sarkosiini vahelise reaktsiooni tulemused. On järeldatud, et kui halogeeni asendamisel (esterside säilib) kasutada sekundaarse radikaaliga estreid või bromoetaanhappe estreid, on saagis hea või rahuldav. Aminohappe vôi aminosulfohappe iseloom avaldab reaktsiooni tulemusele vähe mōju.

\section{H. KIIK, Reet JOONSON, S. FAINGOLD}

\section{SYNTHESIS AND PROPERTIES OF N-(SULPHOETHYL)- AND -N-(CARBO- XYMETHYL)-AMINOACETATES}

1. Reaction of various halogenoacetates with amino and aminosulphonic acids

The reaction of primary and secondary dodecyl chloro- and bromoacetates with taurine and sec. dodecylbromoacetate with taurine, methyltaurine, glycine and sarcosine was investigated. It was found that a substitution of halogen (ester linkages intact) results in good or satisfactory yields in case of esters with secondary alkyl radical and esters of bromoacetic acid. The amino or aminosulphonic acid has a negligible effect on the result of the reaction. 